\title{
The Effects of Dual-Task Gait Training on Gait Performance under Cognitive Tasks in Chronic Stroke
}

\author{
Kyung-hoon $\mathrm{Yu}^{1,2}$, Hye-seon Jeon ${ }^{3,4}$ \\ 'Department of Physical Therapy, Division of Health Science, Baekseok University, Cheonan; ${ }^{2}$ Department of Physical Therapy, The Graduate School, \\ Yonsei University; ${ }^{3}$ Department of Physical Therapy, College of Health Science, Yonsei University; ${ }^{4}$ Department of Ergonomic Therapy, The Graduate \\ School of Health and Environment, Yonsei University, Seoul, Korea
}

Purpose: Walking in the dual-task condition is a critical skill for hemiplegic patients to live in real-life situations. The purpose of this study was to compare the effect of dual-task gait training and general gait training on gait parameters and cognitive function in patients with chronic stroke during dual-task walking.

Methods: The study included 23 patients with chronic hemiparetic stroke who were randomly divided into experimental (dual-task gait training) and control (general walking training) groups. The 11 subjects in the experimental group and nine subjects in the control group received dual-task gait training (walking while handling a ball, crossing obstacles, picking up various objects, and problem solving simple cognitive tasks and general over-ground gait training, respectively, for 30 minutes per day 5 days per week for 4 weeks. Spatiotemporal parameters and cognitive tasks in the dual-task gait condition were measured. Statistical analysis of the changes between the pre- and post-intervention measurement variables was performed using ANCOVA.

Results: In the gait condition under cognitive tasks, the changes pre- and post-intervention in gait velocity, stride length, double support limb, and step symmetry were significantly greater in the dual-task gait training group; however, the dual-task gait training group showed no significant improvement compared to the general gait training group in terms of the assessment of cognitive tasks. Conclusion: The findings suggest that dual-task gait training may be beneficial for walking ability in dual-task walking condition.

Keywords: Dual task, Gait, Training, Cognition, Stroke

\section{서 론}

뇌졸중을 겪는 사람들은 운동, 지각과 인지 기능의 저하로 인해 독립 적인 일상생활과 사회생활의 어려움에 직면하게 된다. 뇌졸중으로 인한 신체활동 부족은 심폐기능 저하, 근력과 보행의 저하와 균형조 절의 어려움을 동반하게 되고, 결국 낙상의 위험으로 공동체 생활의 참여의 기회가 줄어들게 된다.3.4

보행은 가장 잘 프로그램화 된 운동 기능 중 하나로서 예측 가능 한 상황에서는 중추패턴발생기(central pattern generator, $\mathrm{CPG}$ )에 의해

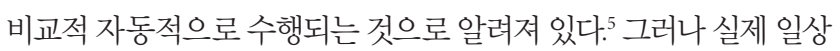
생활은 수행자가 도구의 사용, 물건 나르기, 대화하기 등이 동시에 요 구 되는 경우가 많기 때문에 보행을 하는 시점의 환경적 상황을 적절 하게 반영해야 한다. 따라서 보행은 단지 자동적인 사지의 역학적인 움직임만으로 수행되는 것이 아니라, 집중, 계획, 기억, 집행기능과 같
은 다른 인지 과정들이 동시에 진행된다. ${ }^{6}$ 예를 들어 걷는 중에 대화 하기와 같이 일상생활에서 수행하는 이중과제(dual-task)는 인지와 운동과제들을 환경과 상황에 맞추어 적절히 주의력을 분배가 요구 된다. 노인들과 뇌졸중 환자들은 이중과제 수행 시 자세조절 또는 보 행과 같은 과제와 이차적인 과제 사이에서 우선순위와 주의력 분배 의 문제로 인해 두 가지의 과제 사이 중 한 부분의 감소 또는 두 과제 모두 감소를 보인다.8-10

뇌졸중 환자들이 보행 중에 계산하기, 시간 맞추기와 자발적인 말 하기 등과 같은 이중과제를 수행할 때 보행만 하는 집단에 비해 보행 속도의 감소, 보폭(stride length)의 감소, 두 다리의 보행간격(step length)의 비대칭, 길어진 두 다리 지지기(double limb support), 긴 디딤 기(stance phase)와 상대적으로 짧은 흔들기(swing phase) 등의 차이를 보였다.911,12 감소한 공간 보행변수와 증가한 시간 보행변수들은 낙상 의 경험이 있는 노인들과 신경학적 문제를 지닌 자들에게 보일 수 있 
는 특징이며, ${ }^{13}$ 이중과제 수행의 어려움에 직면하게 된다. 뇌졸중 환자 의 보행 훈련에 있어 기능이 감소된 보행 변수들의 증진은 낙상 예방 과 실제 환경에서 안전한 보행의 중요한 목표가 된다. ${ }^{14}$

뇌졸중 환자들의 균형과 보행에 효과적인 다양한 훈련들이 있지만, 실제 환경에서 보행의 증진을 위해선 보행과 동시에 일상생활 수행능 력을 향상에 도움을 줄 수 있는 이중과제훈련이 필요하다. ${ }^{15-22}$ 최근에 는 공을 차면서 보행을 실시하는 훈련과 균형과 보행 시 인지과제를 함께 수행하는 훈련, 점진적인 보행훈련 시 손으로 다룰 수 있는 과제 를 함께 수행하는 훈련들과 같은 이중과제훈련을 보고하였다.23-25 이 중과제훈련 연구들의 결과는 주로 보행속도 또는 균형 변수의 변화 와 효과로 보고하였으나 균형과 보행능력의 향상만이 일상생활에서 의 기능의 향상과 밀접한 관계가 있다고 보기는 어렵다. 따라서 본 연 구에서는 만성 뇌졸중 환자에게 이중과제 보행 훈련을 통해 실제 환 경에서의 이중과제 보행의 개선을 보여주기 위해서 보행 시 주의력과 집행기능의 처리능력 변화를 알아보고자 연구를 실시하였다.

본 연구의 목표는 만성 뇌졸중 환자에게 이중과제 보행훈련이 인 지-이중과제 보행 조건에서 보행과 인지과제 해결능력에 미치는 효 과를 알아보기 위한 것이다.

\section{연구방법}

\section{1. 연구대상}

본 연구는 뇌졸중으로 고생하는 환자를 대상으로 실시하였으며, 사 전에 대상자에게 실험의 방법과 절차들을 자세히 설명하였으며, 동 의서에 서명한 23 명의 대상자를 무작위로 실험군 12 명과 대조군 11 명 으로 나누어 시작하였으나, 실험 중간에 건강상 퇴원 등의 사유로 3 명이 탈락하여 실험군 11 명, 대조군 9 명으로 실험을 실시하였다. 대상 자 선정 기준은 뇌졸중 진단 후 6 개월에서 3 년 이하인 자, 보조도구의 도움 없이 최소 $10 \mathrm{~m}$ 걸을 수 있는 자, 한국어판 간이 정신상태 검사 에서 20점 이상인자로 실험을 진행하는데 간단한 지시나 설명을 이 해할 수 있는 자로 정했다. ${ }^{26}$ 대상자 제외 기준은 심각한 심장질환 있 는 자, 보행을 할 수 없는 정형외과적 상태인 자, 소뇌 또는 균형에 문 제를 일으킬 수 있는 자 등으로 정하였다. 본 연구는 글로리병원 연구 윤리심의위원회의 승인받았다(Glory 2011021501). 대상자의 일반적인 특성은 다음과 같다(Table 1).

\section{2. 실험방법}

1) 측정도구

본 연구는 보행과 동시에 인지과제를 수행하는 이중과제 조건에서 공간변수와 인지능력 평가를 측정하였다. 보행 측정 시 대상자의 안 전을 위해 주변정리와 인력을 적절하게 배치하였다.
Table 1. General characteristics of participants

\begin{tabular}{lccc}
\hline & $\begin{array}{c}\text { Experimental } \\
\text { group }\end{array}$ & $\begin{array}{c}\text { Control } \\
\text { group }\end{array}$ & $\mathrm{p}$ \\
\hline Gender (male/female) & $8 / 3$ & $5 / 4$ & 0.450 \\
Age (year) & $53.2 \pm 14.3^{*}$ & $56.1 \pm 13.6$ & 0.648 \\
Post-stroke duration (month) & $16.6 \pm 11.1$ & $17.3 \pm 9.2$ & 0.882 \\
Etiology (infarction/hemorrhage) & $6 / 5$ & $4 / 5$ & \\
Side of hemiparesis (right/left) & $5 / 6$ & $4 / 5$ & \\
Brunnstrum's stage (stage 3/stage 4) & $5 / 6$ & $4 / 5$ & \\
MMSE-K & $27.6 \pm 3.6$ & $26.6 \pm 3.8$ & 0.542 \\
\hline
\end{tabular}

MMSE-K: Mini-Mental State Examination-Korean. ${ }^{*}$ Mean \pm SD.

\section{(1) 시공간 보행변수(spatiotemporal gait parameters)}

휴대용 보행분석 시스템인 GAITRite (CIR system Inc., Havertown, PA. USA)는 $3.7 \mathrm{~m}$ 의 길이와 $0.6 \mathrm{~m}$ 폭의 센서가 들어 있는 카페트를 이동 통로로 사용하고 컴퓨터에서 발자국을 감지하여 시간, 공간 데이터 로 변환된다. 이 시스템은 젊은 성인과 노인들에게 높은 측정-재측정 신뢰도와 $3 \mathrm{D}$ 동작분석기와 높은 동시타당도를 보고하였다. ${ }^{2728}$ 주요 측정변수로 마비쪽 다리의 보행속도 $(\mathrm{cm} / \mathrm{s})$, 보폭 $(\mathrm{cm})$, 두 다리 지지기 (\% 보행주기)와 보행간격 대칭성(step symmetry)을 선택하였다. 보행 간격 대칭성은 건측 보행간격/환측 보행간격로 나타내며, 1 과 가까울 수록 양쪽 다리가 대칭이다 볼 수 있다. ${ }^{29}$ 치료적 중재 전후 측정은 대 상자에게 아무런 지지 없이 평상시에 걷는 속도로 $10 \mathrm{~m}$ 를 걸으며, 중 간에 GAITRite를 위치시켰고 보행 중에 인지과제를 동시에 수행하 는 이중과제 조건에서 측정하였다. 보행 중에 대상자는 정면에 위치 한 스크린의 여러 종류의 사물들로 구성된 사진들을 보고 이름을 말 하며 걷게 된다. 중간에 멈추거나 보행분석기를 벗어나게 되면 재측 정하며 이를 대상자 간의 학습효과를 위해 평가 장소에 측정하는 대 상자만 들어가게 하였으며, 총 3 번 실시하여 평균값을 이용하여 데이 터를 얻었다.

\section{(2) 인지과제 평가}

보행과 동시에 인지과제를 수행하는 이중과제 조건 시 주의력과 집 행기능의 변화를 통해 인지과제의 수행능력을 평가하기 위해 대상 자는 $10 \mathrm{~m}$ 보행 중에 스크린에 보이는 일상에서 친숙한 사물의 이름 을 말하게 된다. 과일, 채소 등 쇼핑과 관련된 여러 사물들과 일상생 활에서 쉽게 접할 수 있는 물건 등의 50 개의 사물의 사진을 컴퓨터에 무작위로 순서로 준비하였으며, 사전에 대상자에게 사물의 사진을 미리 보여주어 대상자가 장기기억 및 회상할 수 있도록 하였다. ${ }^{8,30}$ 보 행하는 동한 대상자가 이름을 맞추거나 통과라고 말하면 다음 사진 으로 넘어가게 되며, 정확히 답한 사물의 수를 계산하여 데이터로 사 용하였다. 


\section{3. 보행훈련}

실험군과 대조군은 하루 30 분, 주 5 회, 4 주간 총 20 회를 훈련에 참여 하였으며, 실험군은 이중과제보행훈련, 대조군은 일반적인 보행훈련 을 실시하였다. 대상자들은 하루에 1 시간씩 다리, 팔 관절운동, 근력 운동, 균형운동과 같은 일상적인 물리치료를 받았으며, 총 치료시간 은 동일하였다.

\section{1) 이중과제 보행훈련군(dual-task gait training group)}

실험군은 과제-지향적 보행훈련(task-oriented gait training)을 기반으 로 이중과제 보행훈련을 실시하였으며23,31 총 3가지로 구성된 보행훈 련 과제로 구성하였다. 과제 1 은 공을 차거나 손으로 튕기면서 걷기를 실시하였으며, 과제 2 는 경사면과 불안정한 지면, 장애물 피하기와 계 단 오르고 내려가기, 과제 3 은 쇼핑 카트를 밀면서 여러 높이에 위치 한 다양한 물건을 담기를 실시하였다. 과제 4 는 보행훈련 시 숫자 더 하기와 빼기와 쇼핑물건 계산하기, 단어 말하기 (쇼핑, 과일 등), 끝말 잊기 등의 간단한 인지과제를 포함하였다. 모든 보행훈련 과제는 환 자 개인의 능력에 맞추어 실시하였으며, 훈련 초기엔 주로 보행 과제 와 다른 과제를 나누어 실시하였으며, 충분한 반복을 통해 운동 기술 이 향상되면 점진적으로 동시에 수행할 수 있도록 하였으며, 6.5 분 훈 련을 실시하고 1 분 휴식시간을 주었다(Table 2).

\section{2) 일반 보행훈련군}

대조군은 일반적인 보행훈련을 실시하였다. 실험군과 동일한 훈련과

Table 2. Tasks of dual-task gait training

\begin{tabular}{|c|c|c|c|c|}
\hline & Task 1 & Task 2 & Task 3 & Task 4 \\
\hline $\begin{array}{l}\text { Experimental } \\
\text { group }\end{array}$ & $\begin{array}{l}\text { Walking while } \\
\text { handling a ball } \\
\text { (bouncing a } \\
\text { ball, throwing } \\
\text { and catching a } \\
\text { ball, kicking a } \\
\text { ball) }\end{array}$ & $\begin{array}{l}\text { Walking while } \\
\text { crossing } \\
\text { obstacles } \\
\text { (s-shape and } \\
\text { uneven } \\
\text { surfaces) and } \\
\text { stairs }\end{array}$ & $\begin{array}{l}\text { Walking while } \\
\text { picking up } \\
\text { various objects } \\
\text { during push- } \\
\text { ing a shopping } \\
\text { cart }\end{array}$ & $\begin{array}{l}\text { Cognitive tasks } \\
\text { (simple } \\
\text { addition and } \\
\text { subtraction, } \\
\text { verbal fluency } \\
\text { task) }\end{array}$ \\
\hline Control group & \multicolumn{4}{|c|}{ General overground gait training } \\
\hline $\begin{array}{l}\text { Level of } \\
\text { difficulty }\end{array}$ & \multicolumn{4}{|c|}{$\begin{array}{l}\text { Each task was graded and progressed according to the } \\
\text { subject's functional level }\end{array}$} \\
\hline
\end{tabular}

휴식시간으로 치료실을 걷는 훈련을 실시하였다. 안전과 훈련을 위 해 대상자 한 명에 치료사를 한 명이 도와주었다.

\section{4. 분석방법}

본 연구에서 수집된 자료들은 SPSS ver 18.0 (SPSS Inc. Chicago, IL, USA) 프로그램을 이용하여 자료를 분석하였다. 실험군과 대조군의 일반적인 특성에 차이가 있는지 알아보기 위해 독립 t검정을 사용하 였다. 보행훈련의 효과를 분석하기 위해 공분산분석(Analysis of Covariance, ANCOVA)을 실시하였으며, 보행훈련 전 값을 공변량(covariate)으로 사용하여 분석하였다. 통계학적 유의수준은 $\alpha=0.05$ 로 하였다.

\section{결 과}

인지 이중과제 조건에서 실험군과 대조군의 훈련 전후의 보행변수와 두 집단 간의 차이를 보여준다. 실험군에서 보행속도, 보폭, 두 다리 지지기의 보행변수와 걸음걸이 대칭성이 대조군에 비해 통계학적으 로 유의하게 증진되었다 $(\mathrm{p}<0.05)$. 또한 인지 이중과제 보행 조건 시 인지 이중과제 평가를 보여주며, 실험군과 대조군 모두 정답을 맞힌 개수가 증가되었지만 통계학적으로 유의한 차이는 없었다(Table 3).

\section{고 찰}

본 연구는 만성 뇌졸중 환자들에게 일상생활의 보행과 비슷한 상황 으로 구성된 이중과제 보행훈련이 보행과 동시에 인지과제를 수행하 는 이중과제 조건에서 보행변수와 인지능력의 향상에 도움을 주는 지 알아보기 위함이다. 이중과제 보행훈련군은 일반 보행훈련군에 비해 이중과제 보행 환경에서 보행능력 개선에 더욱 효과적임을 알 수 있었다.

최근 만성 뇌졸중 환자에게 트레드밀 보행 동안 소리 신호에 따라 고리를 옮기는 인지-운동 이중과제 훈련을 적용 시 트레드밀 훈련군 에 비해 정적 균형이 향상되었으며, 이로 인해 정적 균형의 증진으로 보행에 긍정적인 영향을 미칠 수 있었다. $\operatorname{Sim}^{32}$ 과 $\mathrm{Oh}^{33}$ 의 연구에서 일

Table 3. Comparison of spatiotemporal gait parameters and cognitive test in cognitive dual-task condition

\begin{tabular}{|c|c|c|c|c|c|}
\hline \multirow{2}{*}{ Variables } & \multicolumn{2}{|c|}{ Experimental group } & \multicolumn{2}{|c|}{ Control group } & \multirow{2}{*}{$\mathrm{p}$} \\
\hline & Pre-intervention & Post-intervention & Pre-intervention & Post-intervention & \\
\hline Velocity $(\mathrm{cm} / \mathrm{s})$ & $138.53 \pm 53.11^{*}$ & $152.19 \pm 58.35$ & $97.51 \pm 38.47$ & $96.71 \pm 33.10$ & $0.038^{+}$ \\
\hline Stride length $(\mathrm{cm})$ & $68.60 \pm 22.84$ & $74.34 \pm 24.31$ & $49.78 \pm 19.14$ & $49.79 \pm 19.05$ & $0.047^{\ddagger}$ \\
\hline Double limb support (\%) & $32.23 \pm 7.52$ & $29.34 \pm 7.49$ & $39.27 \pm 16.79$ & $39.33 \pm 15.89$ & $0.008^{+}$ \\
\hline Step symmetry & $0.96 \pm 0.34$ & $1.05 \pm 0.28$ & $0.91 \pm 0.33$ & $0.89 \pm 0.29$ & $0.025^{+}$ \\
\hline Cognitive dual-task test $^{+}$ & $11.64 \pm 2.26$ & $12.09 \pm 1.97$ & $10.96 \pm 1.88$ & $11.03 \pm 1.89$ & 0.086 \\
\hline
\end{tabular}

${ }^{*}$ mean $\pm S D,{ }^{+}$number of correct answers, ${ }^{\dagger} p<0.05, p$-value is comparison of experimental and control data using ANCOVA (covariate $=$ pre-intervention value). 
상생활에서 빈번히 사용되는 물 컵 옮기기와 계란 옮기기를 적용한 인지운동 이중과제 훈련 집단이 단순 보행훈련 집단에 비해 $10 \mathrm{~m}$ 보 행검사와 일어서 걷기 검사에서 향상을 보였는데, 이 결과는 이중과 제 훈련은 일상생활에서 주의력을 적절하게 분배하여 다양한 과제 학습에 도움을 주며 인지능력의 협응의 향상으로 보행능력이 향상 되었다고 언급했다. 본 연구에서 이전 연구의 결과와 유사하게 이중 과제 보행훈련을 실시한 대상자들이 일반 보행훈련군에 비해 보행속 도가 향상되었다.

뇌졸중 환자들은 이중과제 조건의 간섭으로 보폭의 감소, 보폭, 분 당 보행률(cadence) 등과 같은 보행변수들이 감소하며, 보행 시 균형 과 다른 과제를 수행하는 데 어려움을 갖는다. ${ }^{9}$ 본 연구에서 이중과 제 보행훈련군이 일반보행훈련군에 비해 복잡한 이중과제 보행조건 에서 보폭이 증가해 수행능력이 개선되었음을 알 수 있었다. 이중과 제 보행훈련군이 일반 보행훈련군에 비해 두 다리 지지기가 감소를 했으며, 보행간격의 비대칭성도 줄어들었다. 뇌졸중 환자들이 이중과 제를 수행할 때 두 다리 지지기와 보행변수들의 비대칭성의 증가는 뇌졸중 환자들에게 있어 수행능력의 감소를 보여주는 의미 있는 변 수들이다. 34,35 따라서 보행 중 인지과제를 해결하는데 있어 과제 사이 의 간섭효과가 줄어들어 이중과제 보행훈련군의 보행 수준이 더욱 향상되었다고 생각된다.

인지과정(cognitive process)은 운동학습의 중요한 부분으로 인지과 정의 개선은 뇌졸중 환자들의 입원기간 또는 퇴원 후에 향상된 운동 기술과 일상생활 수행을 향상시키고 유지할 수 있도록 도움을 줄 것 이다. ${ }^{36} J u n g$ 과 $\mathrm{Won}^{37}$ 의 연구에서는 인지과제를 포함한 이중과제 훈 련을 뇌졸중 환자에게 적용하여 보행속도와 균형에 향상을 보였으 며, 점진적으로 인지과제에 주의력의 조절이 가능해져 인지능력도 어느 정도 개선되었다고 했다. Pellecchia ${ }^{38}$ 의 연구에서 이중과제 훈련 집단이 단일과제 훈련 집단에 비해 균형과 인지과제를 동시에 수행 했을 때 자세동요가 감소하는 것을 알 수 있었다. 하지만 이중과제 훈 련을 통해 균형과 인지과제의 수행능력이 동시에 향상된 것으로 볼 수 있으나 균형 능력이 증가된 것이 인지과정이 개선되었다고 볼 수 는 없다고 저자는 언급했다. 본 연구는 보행과 동시에 인지과제를 수 행하는 조건하에 보행과 인지과제의 변화를 측정했지만, 향상된 보 행변수에 비해 인지과제의 해결능력은 큰 변화가 없었다. 이중과제 보행훈련군은 주로 보행을 우선시하여 훈련을 진행하였으며, 집중적 인 인지훈련은 부족하여 뇌졸중 대상자들의 인지과정의 개선은 부 족했다고 생각된다.

최근 연구에서 인지-운동 이중과제 보행훈련이 이중과제 조건에 서 보행능력의 증진은 인지와 보행과제 간의 간섭 효과가 줄어들어 이로 인해 실행기능(executive function)의 향상이 되었음을 언급했지 만, ${ }^{39}$ 본 연구에서는 이중과제 보행훈련군이 보행변수들의 향상에 비
해 인지과제의 해결능력의 개선은 부족함을 알 수 있었다. 일상생활 에서 수행하는 이중과제의 일반적인 과정은 먼저 시작한 과제의 자 극의 반응시간이 마무리 될 때까지 두 번째 과제의 자극을 선택하는 시간이 지연되는데, 이런 현상을 반응-선택 병목현상(bottleneck phenomenon)이라고 한다..$^{40}$ 비록 인지과제 해결능력의 향상되진 않았지 만 인지과제를 수행하는 동안 보행이 향상된 것은 이중과제 보행훈 련이 보행의 자동화에 도움을 주어 인지과제의 간섭이 큰 영향을 미 치지 않았다고 판단할수 있다.

본 연구의 제한점은 첫째, 대상자수가 적어 만성 뇌졸중환자에게 일반화하기에는 어려움이 있으며, 둘째는 이중과제 보행훈련과 일반 보행훈련 집단의 일반적인 특성들의 동질성을 확보하여 무작위 할당 하였으나 초기 보행능력의 차이가 있었으며 이를 위해 통계학적 방 법을 이용하여 검증하려 했으나, 결과적으로 본 연구에 영향을 미칠 수도 있다는 것이다. 셋째, 뇌졸중 환자의 인지기능이 개선되기엔 인 지훈련이 부족하였으며 기간이 짧았다. 따라서 위에 제시된 제한점 을 보완하여 일상생활에 도움을 줄수 있는 이중과제 보행 즉, 인지와 보행 간의 주의력을 유연하게 분배할 수 있는 보행훈련 연구가 필요 할 것이다.

본 연구는 만성 뇌졸중 환자에게 4 주간 이중과제 보행훈련을 적용 후 인지과제를 수행하며 보행하는 인지-이중과제 보행 조건에서 보 행변수들의 변화와 인지능력에 변화를 알아보고자 하였다. 이중과 제 보행훈련을 실시한 집단에서 일반보행훈련을 실시한 집단에 비해 시공간 보행변수가 유의한 향상을 보였지만, 인지능력 평가에선 향 상을 했지만 통계적인 차이는 없었다. 본 연구에서 만성 뇌졸중 환자 에게 이중과제 보행훈련을 적용한 경우 보행수준의 향상으로만 뿐 아니라 연구가 부족했던 인지과제 해결능력의 변화도 알 수 있는 정 보를 제공하였다. 이중과제 보행훈련을 통해 뇌졸중 환자들의 삶의 질 향상을 위해 보다 명확한 근거를 위해 앞으로 연구가 지속되어야 할 것이다.

\section{REFERENCES}

1. Mercier L, Audet T, Hebert R et al. Impact of motor, cognitive, and perceptual disorders on ability to perform activities of daily living after stroke. Stroke. 2001;32:2602-8.

2. Ryan A, Dobrovolny CL, Silver KH et al. Cardiovascular fitness after stroke: Role of muscle mass and gait deficit severity. J Stroke Cardiovasc Dis. 2000;9:185-91.

3. Dettmann MA, Linder MT, Sepic SB. Relationships among walking performance, postural stability, and functional assessments of the hemiplegic patient. Am J Phys Med. 1987;66:77-90.

4. Weerdesteyn V, de Niet M, van Duijnhoven HJ et al. Falls in individuals with stroke. J Rehabil Res Dev. 2008;45:1195-214.

5. Nielsen JB. How we walk: Central control of muscle activity during hu- 
man walking, Neuroscientist. 2003;9:195-204.

6. Mulder T, Zijlstra W, Geurts A. Assessment of motor recovery and decline. Gait Posture. 2002;16(2):198-210.

7. Yogev-Seligmann G, Hausdorff JM, Giladi N. The role of executive function and attention in gait. Mov Disord. 2008;23(3):329-42.

8. Hyndman D, Ashburn A, Yardley L et al. Interference between balance, gait and cognitive task performance among people with stroke living in the community. Disabil Rehabil. 2006;28:849-56.

9. Plummer-D’Amato P, Altmann LJ, Saracino D et al. Interactions between cognitive tasks and gait after stroke: a dual task study. Gait Posture. 2008;27(4):683-8.

10. Siu KC, Chou LS, Mayr U et al. Does inability to allocate attention contribute to balance constraints during gait in older adults? J Gerontol A Biol Sci Med Sci. 2008;63:1364-9.

11. Bowen A, Wenman R, Mickelborough J et al. Dual-task effects of talking while walking on velocity and balance following a stroke. Age Ageing. 2001;30:319-23.

12. Dault MC, Geurts ACH, Mulder TW et al. Postural control and cognitive task performance in healthy participants while balancing on different support-surface configurations. Gait Posture. 2001;14:248-55.

13. MacAulay RK. Allaire TD, Brouillette RM et al. Longitudinal assessment of neuropsychological and temporal/spatial gait characteristics of elderly fallers: Taking it all in stride. Front Aging Neurosci. 2015;7(34):1-8.

14. van de Port IG, Kwakkel G, van Wijk I et al. Susceptibility to deterioration of mobility long-term after stroke: A prospective cohort study. Stroke. 2006;37(1):167-71.

15. Choi JH, Park SH. The effect of dual-task training on a serial reaction time task for motor learning. J Kor Phys Ther. 2012;24(6):405-8.

16. Hwang S, Jeon HS, Yi CH et al. Locomotor imagery training improves gait performance in people with chronic hemiparetic stroke: A controlled clinical trial. Clin Rehabil. 2010;24(6):514-22.

17. Kim SH, Choi JD. The effect of gait training of progressive increasing in body weight support and gait speed on stroke patients. J Kor Phys Ther. 2013;5(5):252-9.

18. Hong SI, Bang DH, Shin WS. Effects of side walking training with elastic-band on gait and balance of stroke patients. J Kor Phys Ther. 2014;6(5):372-8.

19. Cho MK., Kim JH., Chung Y et al. Treadmill gait training combined with functional electrical stimulation on hip abductor and ankle dorsiflexor muscles for chronic hemiparesis. Gait and Posture. 2015;42(1):73-8.

20. Lim CG. The Effects of proprioceptive neuromuscular facilitation (PNF) Pattern Exercise Using the Sprinter and the Skater on Balance and Gait Function in the Stroke Patients. J Kor Phys Ther.2014;26(4):249-56.

21. Park SK, Park SH. The effect of water-based exercise on physiological cost index and balance in stroke patients. J Kor Phys Ther. 2014;6(6): 411-7.

22. Lloréns R, Gil-Gómez JA., Alcañiz M et al. Improvement in balance using a virtual reality-based stepping exercise: A randomized controlled trial involving individuals with chronic stroke. Clinical Rehabilitation. 2015;29(3):261-8.

23. Yang YR, Wang RY, Chen YC et al. Dual-task exercise improves walking ability in chronic stroke: A randomized controlled trial. Arch Phys Med
Rehabil. 2007;88:1236-40.

24. Kim GY, Han MR, Lee HG. Effect of Dual-task Rehabilitative Training on Cognitive and Motor Function of Stroke Patients. J Phys Ther Sci. 2014;26(1):1-6

25. Kim HA, Lee HM, Seo KC. The Effects of Dual-Motor Task Training on the Gait Ability of Chronic Stroke Patients J Phys Ther Sci. 2013;25:31720.

26. Folstein M, Folstein SE, McHugh PR. "Mini-Mental State" a Practical Method for Grading the Cognitive State of Patients for the Clinician. Journal of Psychiatric Research. 1975;12(3):189-98.

27. Menz HB, Latt MD, Tiedemann A et al. Reliability of the GAITRite walkway system for the quantification of temporo-spatial parameters of gait in young and older people. Gait Posture. 2004;20(1):20-5.

28. Stokic DS, Horn TS, Ramshur JM et al. Agreement between temporospatial gait parameters of an electronic walkway and a motion capture system in healthy and chronic stroke populations. Am J Phys Med Rehabil. 2009;88(6):437-44.

29. Patterson KK, Parafianowicz I, Danells CJ et al. Gait asymmetry in community-ambulating stroke survivors. Arch Phys Med Rehabil. 2008;89: 304-10.

30. Damian MF, Vigliocco G, Levelt WJ. Effects of semantic context in the naming of pictures and words. Cognition. 2001;81(3):77-86.

31. van de Port IG, Wevers L, Roelse $\mathrm{H}$ et al. Cost-effectiveness of a structured progressive task-oriented circuit class training programme to enhance walking competency after stroke: The protocol of the FIT-Stroke trial. BMC Neurol. 2009;13:9-43.

32. Choi W, Lee G, Lee S. Effect of the cognitive-motor dual-task using auditory cue on balance of surviviors with chronic stroke: A pilot study. Clin Rehabil. 2014;13:1-8.

33. Sim SM, Oh DW. Effect of Dual-task Training With Cognitive Motor Task on Walking and Balance Functions in Patients With Chronic Stroke: Randomized Controlled Pilot Study. Phys Ther Korea. 2015; 22(2):11-20.

34. Plummer-D'Amato P, Altmann LJ, Behrman AL et al. Interference between cognition, double-limb support, and swing during gait in community-dwelling individuals poststroke. Neurorehabil Neural Repair. 2010;24(6):542-9.

35. Kim JH. Relationship between gait symmetry and functional balance, walking performance in subjects with stroke. J Kor Phys Ther. 2014; 26(1):1-8.

36. McEwen SE, Huijbregts MP, Ryan JD et al. Cognitive strategy use to enhance motor skill acquisition post-stroke: a critical review. Brain Inj. 2009;23(4):263-77.

37. Jung SR, Won JI. Effects of Dual-Task Training on Balance and Gait Performance in Patients With Stroke. Phys Ther Korea. 2014;21(2):18-27.

38. Pellecchia GL. Dual-task training reduces impact of cognitive task on postural sway. J Mot Behav. 2005;37(3):239-46.

39. Plummer P, Villalobos RM, Vayda MS et al. Feasibility of dual-task gait training for community-dwelling adults after stroke: a case series. Stroke research and treatment. 2014;9:1-12.

40. Pashler H. Dual-task interference in simple tasks: Data and theory. Psychol Bull. 1994;116(2):220-44. 